\title{
A GEOGRAFIA RURAL E A RENDA DA TERRA
}

\author{
Rural Geography and land rent
}

Geografía Rural y los rendimentos de la tierra

Luiz Fernando Mazinni Fontoura*

* Mestre em sociologia pela UFRGS e Doutor em geografia pela USP

- luiz.fontoura@ufrgs.br

Recebido em 01/10/2019. Aceito para publicação em 19/11/2019.

Versão online publicada em 09/03/2020 (http://seer.ufrgs.br/paraonde)

\section{Resumo:}

Este trabalho visa relacionar o modo de vida no meio rural e a renda da terra. Para isto examina alguns autores da Geografia Rural sobre o conceito de modo de vida e a relação com as transformações das populações e meio. A base da identificação ou visualização dos segmentos rurais é a utilização dos sistemas de produção, ou seja, o nível de absorção de técnicas e especialização da produção. Deste ponto, parte-se para uma discussão sobre a renda fundiária em vários autores, procurando ressaltar a influência dos agentes causadores de diferenciação sobre a população, exemplificando-se alguns casos. Conclui-se com um quadro síntese da relação entre os fatores determinantes da renda, alta e baixa, e as condições de adaptação dos segmentos populacionais relacionados.

Palavras-chave: Geografia Rural. Renda da terra. Modo de vida. População rural

\begin{abstract}
:
This paper aims to relate rural lifestyle and land rent. For this purpose, it examines the literature on Rural Geography regarding the concept of lifestyle and its relationship with population and environmental transformations. The basis for identification or visualization of rural segments is provided by the use of production systems, i.e. the level of absorption of techniques and specialization of production. Then, a discussion about land rent according to several authors takes place, with emphasis on the impact of the agents that bring about differentiation on the population, and some examples are given. Finally, a summary table of the relationship between the determinants of income (high and low), and the capacity for adaptation of the related population segments is presented.
\end{abstract}

Keywords: Rural geography. Land rent. Lifestyle. Rural population.

\section{Resumen:}

El objeto de este trabajo es relacionar la forma de vida en el medio rural y los rendimientos de la tierra. Para ello, examina a algunos autores de Geografía Rural acerca del concepto de forma de vida y la relación con las transformaciones de las poblaciones y el medio. La base de la identificación o visualización de segmentos rurales es el uso de los sistemas de producción, es 
decir, el nivel de absorción de las técnicas y la especialización de la producción. A partir de este punto se empieza una discusión con varios autores sobre los ingresos agrarios, buscando destacar la influencia de los agentes diferenciadores en la población, con ejemplos de algunos casos. Concluye con una síntesis de la relación entre los determinantes de los ingresos, altos y bajos, y las condiciones de adaptación de los segmentos de población relacionados.

Palabras clave: Geografía Rural. Rendimientos de la tierra. Forma de vida. Población rural.

\section{Introdução}

A Geografia Rural é a geografia do campo, onde a terra é o principal meio de produção, ou seja, da porção territorial que fica fora dos limites da cidade. No campo podemos encontrar o que diretamente depende da terra, que pertence à atividade agrária, composta da lavoura e da criação. Presentes no campo ainda estão os elementos que auxiliam e viabilizam esta atividade, como as estradas, as pontes, os silos, os canais de irrigação, as escolas, entre outras coisas, que não dependem diretamente da terra, mas estão presentes no campo.

As vantagens locacionais naturais, como a fertilidade natural, o grau de declividade ou a disponibilidade de recursos hídricos, são importantes fatores que podem atuar como uma possibilidade de ganho diferencial entre os produtores rurais. As vantagens locacionais artificiais são aquelas que procuram minimizar os obstáculos aos ganhos diferenciais naturais ou potencializar os fatores favoráveis a um ganho maior. Os fatores que geram uma renda diferencial no campo e a sua relação com o modo de vida é o que se pretende desenvolver neste trabalho.

Dentro da Geografia Humana e da Geografia Rural existe um conceito fundamental que atravessa toda sua história: o conceito de modo de vida. Derivado do conceito de gênero de vida, formulado por Paul Vidal de La Blache, descreve Derruau (1982, p. 169): "Para a geografia humana, um modo de vida refere-se a uma coletividade. Podemos defini-lo como o conjunto de hábitos pelos quais o grupo que os pratica assegura a sua existência...", através da utilização de instrumentos, técnicas e costumes desenvolvidos por uma sociedade ao longo do tempo. Mais do que isto, o modo de vida se refere a uma forma de adaptação de uma sociedade ao meio, com uma aquisição de conhecimentos que é transmitida de uma geração para outra através dos tempos.

Em razão disto, existem muitos modos de vida graças à diversidade dos meios que compõem a natureza e às formas de adaptação pela atividade humana. Até a Revolução Industrial as técnicas eram muito variadas, e a padronização do uso do solo para se produzir era pequena, aumentando as diferenças entre a produção no campo. Para Derruau (1982, p. 173):

Não há modos de vida perenes. Mesmo quando não recebe influências externas, um modo de vida modifica-se mais rapidamente ou mais lentamente pela invenção de técnicas novas ou por modificações demográficas. O modo de vida pode, inversamente, ser 
modificado por uma transformação social: o desenvolvimento da grande propriedade na Inglaterra provocou uma intensificação da agricultura e um aumento da criação de gado em prados fechados. A revolução industrial modificou, por seu turno, e profundamente, os vários modos de vida praticados na Europa Ocidental, bem como a projeção que estes tinham nas regiões ultramarinas, por efeito da colonização.

Antes mesmo da Revolução Industrial já havia alterações nas formas de modo de vida do colonizador e do colonizado, impondo-se ao antigo, ou misturando formas, tanto impostas pela natureza como pela sociedade, como continua Derruau (1982, p. 176):

De resto, não é apenas a mobilização dos recursos locais que vai explicar o modo de vida, mas o tipo econômico que preside a essa mobilização de recursos. A geografia deve, pois, mudar o ponto de vista tradicional pelo qual encara as realidades. É obrigada a deixar de conceber o meio físico como o grande fator explicativo, bem como a não procurar as causas essenciais nos mecanismos e organismos invisíveis desse meio físico. Já não basta estudar o trabalho, torna-se necessário ter em consideração o banco, a bolsa, a sociedade anônima, o gabinete de planificação. O modo de vida é a resposta de um grupo à organização econômica e social que lhe é imposta ou que ele impõe a si próprio.

A especialização da produção agrícola levou à dependência da produção dos fatores dos sistemas de cultivo através da artificialização das condições para a adequação ao meio, como o uso de fertilizantes com vistas à melhor utilização do meio em busca da produtividade. Para isto ocorrer, o grupo vai ter que se adaptar a um tipo de organização econômica que não depende só dele, sendo externo ao grupo, referente ao mercado ou à planificação política. "A geografia é precisamente aquela ciência que vai sem cessar, de um a outro ponto de vista, isto é, a ciência que estuda as diferenciações espaciais no interior de um mesmo sistema de produção, e as diferenciações econômicas e sociais no interior de um mesmo esquema físico." (DERRUAU, 1982, p. 178)

Ao iniciar seu estudo de Geografia Humana, Brunhes (1962, p. 25) escreve sobre a importância do calor solar sobre o nosso planeta como o "grande princípio de toda a atividade humana", principalmente no ponto de contato da atmosfera e da crosta terrestre, onde se encontram todos os fenômenos da vida vegetal, animal e humana. Brunhes descreve que a Terra não está parada no espaço, que é animada por movimentos periódicos, em virtude da sua posição em relação ao Sol, como na citação abaixo:

Sobre o globo terrestre, a radiação solar é, portanto, uma causa sem fim de desequilíbrio e, por conseguinte, de movimento. Mas esse movimento seria desordenado se não existisse, para combater tal desordem, uma causa geral de ordem; esta força que chamarei força sábia da Terra, em oposição à força louca do Sol, é a atração centrípeta do peso. Impõe aos corpos diferentes pesos, diferentes densidades, uma só ordem de estabilidade, um só modo de equilíbrio. Finalmente, uma obra una e regular dessa luta entre uma causa infatigável de atividade e uma causa de ordem inviolável.

Essa atração dos corpos mais pesados para o centro da Terra 
disciplina e organiza a atividade; dessa maneira, uma ordem harmônica se introduz na economia geral do nosso planeta (BRUNHES, 1962, p. 28).

Assim, tudo está em movimento, o palco e as ações humanas estão em transformação. Isto define o princípio da atividade, ou seja, de que tudo está em transformação, o fenômeno humano e o terrestre. "Todos são animados por determinado movimento; é necessário estudá-los como se estudam os corpos em movimento: precisar o ponto do espaço e o momento do tempo em que se produzem; depois, indicar o sentido e observar a rapidez do próprio movimento". (BRUNHES, 1962, p. 32).

O outro princípio descrito por Brunhes é o da conexão, ou seja, que não basta estudar os fenômenos isolados na realidade; todas as coisas estão ligadas umas às outras. A ideia de que a Terra é um todo, e daí os princípios da atividade e da conexão serem estudados juntos, "eis como somos conduzidos a estudar, como geógrafos, a ação do homem na Natureza - sem a separar, nunca, do estudo da Geografia Natural ou Geografia Física" (BRUNHES, 1962, p. 41).

Portanto, avaliar o meio e o modo de vida é imprescindível para a análise geográfica, pois os diferentes tipos de meios e adaptações a este estão diretamente ligados, resultando em diferentes paisagens e apontando a direção das transformações. Para uma classificação quanto às possibilidades de uso da terra, entende-se necessário o uso da análise dos sistemas de produção e sistemas agrários, com a finalidade de se ter a forma de organização econômica de uma comunidade com o seu meio e os demais ramos da sociedade em geral.

Para caracterizar a agricultura, ou seja, o resultado do trabalho social sobre a terra, é importante diferenciar os cultivos (a lavoura) e a criação (a pecuária), em cada tempo, pois as mudanças técnicas, seus atores e território, são variáveis de difícil visualização. É neste sentido que a análise da paisagem e dos sistemas de produção vem a contribuir para os estudos geográficos, pois o objetivo é descobrir o equilíbrio entre a organização e a divisão do trabalho social, da técnica utilizada e o meio, no sentido de identificar os sistemas de produção e os sistemas agrários a partir das marcas deixadas na paisagem. $O$ primeiro, o sistema de produção, segundo Mazoyer \& Roudart (2010, p. 73):

\footnotetext{
...se define pela combinação (a natureza e as proporções) de suas atividades produtivas e de seus meios de produção. A categoria social de um estabelecimento se define pelo estatuto social de sua mão de obra (familiar, assalariada, cooperativa, escrava, serviçal), pelo estatuto do agricultor e pelo seu modo de acesso à terra (livre acesso às terras comunais, reserva senhorial, posses servis, exploração direta, parceria, arrendamento...) e pela dimensão do estabelecimento agrícola.
}

Já numa escala de vila ou região, deve ser utilizado o conceito de sistema agrário, segundo os autores,

O sistema agrário pode ser conceituado como o instrumento intelectual que permite apreender a complexidade de toda forma de agricultura real pela análise metódica de sua organização e de seu

Para0nde!?, Porto Alegre, v.13, n.1, p.21-45, 2020. http://seer.ufrgs.br/paraonde 


\begin{abstract}
funcionamento. Esse conceito permite também classificar inúmeras formas de agricultura identificáveis no passado ou observáveis no presente em um número limitado de sistemas, caracterizados cada um por um gênero de organização e funcionamento. A teoria da evolução dos sistemas agrários é o instrumento que permite representar as transformações incessantes da agricultura de uma região do mundo como uma sucessão de sistemas distintos, que constituem as etapas de uma série histórica definida. Enfim, a teoria da diferenciação dos sistemas agrários é o instrumento que permite apreender suas grandes linhas e explicar a diversidade geográfica da agricultura em uma dada época (Mazoyer \& Roudart, 2010, p. 76).
\end{abstract}

Portanto, é um conjunto de relações que se estabelecem entre as explorações e o espaço que utilizam. O sistema agrário é a expressão espacial da associação de produção e técnicas colocadas em prática por uma sociedade para satisfazer suas necessidades. Exprimem em particular a interação entre um sistema bioecológico representado pelo meio natural e um sistema sociocultural, através de práticas oriundas particularmente da aquisição técnica ou acumulação do conhecimento.

A produção agrícola depende, pois, de uma adequação ao ambiente e do conhecimento do grupo que a produz. Mais uma variável se soma às demais neste momento: a relação com o mercado. Variáveis como distância, grau de investimento em técnicas, preço, transporte, conservação ou perecibilidade dos produtos, entre outras, entram na distribuição espacial da produção.

\title{
2. A incorporação da terra ao modo de produção capitalista
}

A terra é um meio de produção muito especial, pois não é fruto do trabalho individual ou social. Portanto, a terra em si não tem valor, ou seja, não contém trabalho humano. Mas ainda é a base para a produção agrícola ou mesmo do extrativismo mineral ou vegetal. Assim, como escreve Marx (1986, p. 137), "a apropriação da renda é a forma econômica em que a propriedade fundiária se realiza, e, por sua vez, pressupõe a propriedade fundiária, propriedade de determinados indivíduos sobre determinadas frações do globo terrestre". Se paga, portanto, pelo direito de utilização de um bem necessário, mas não pelo trabalho contido nele.

Ao examinar as formas da renda fundiária se manifestar, continua o autor,

... 0 arrendamento que é pago a título de renda fundiária ao proprietário da terra pela utilização do solo, seja para fins produtivos, seja para fins consumptivos, cabe registrar que o preço das coisas que não têm por si nenhum valor, ou seja, que não são produto do trabalho, como a terra, ou que ao menos não podem ser reproduzidas mediante trabalho, como antiguidades, obras de arte de determinados mestres etc., pode ser determinado por combinações casuais. Para vender uma coisa, é preciso apenas que seja monopolizável e alienável (MARX, 1986, p. 137).

A incorporação da terra como meio de produção vai se dando na medida da necessidade social. E esta cresce na mesma razão da população não agrícola,

Para0nde!?, Porto Alegre, v.13, n.1, p.21-45, 2020. http://seer.ufrgs.br/paraonde 
crescendo com isto o mercado e a demanda por produtos da terra, a exemplo dos recursos alimentares e das matérias-primas. Marx alerta para o fato de que é da natureza do modo de produção capitalista a diminuição da população agrícola em relação a não agrícola, pois na agricultura diminui o capital variável em relação ao constante, só aumentando o capital variável na medida em que novas terras são incorporadas, o que pressupõe o crescimento da população não agrícola.

Para que a renda se desenvolva como renda monetária na produção de mercadorias é necessário que a produção agrícola se torne também mercadoria, e isto pressupõe uma população não agrícola, que não produza os produtos da terra, mas dela dependa. Destaca Marx (1983, p. 140) que tanto a produção agrícola como a industrial, isoladamente, não produz valor ou mercadoria. Isto "só se torna valor e mercadoria em determinado contexto social". Mais que isto, "toda mercadoria só pode realizar seu valor no processo de circulação, e se ela o realiza e até que ponto o realiza depende das condições do mercado". Logo, o avanço das relações capitalistas no campo se dá na medida do avanço destes fatores: diminuição da população no campo e o aumento desta na cidade, bem como o consequente aumento da demanda da produção de mercadorias produzidas no campo. Fora disto temos sociedades diferentes da capitalista, onde a produção da subsistência é realizada pela própria população que dela depende, como, por exemplo, os agregados em propriedades rurais.

Esta condição da produção capitalista no campo se desenvolve lentamente, pois depende da expansão desta produção na cidade e da comunicação entre as duas, estreitando a realização de um mercado. A existência de um depende da do outro. O preço da terra vai depender, portanto, de fatores de um determinado contexto social e da expansão urbana.

Ao analisar a renda da terra, Marx leva em conta que os produtos da terra ou da mineração são vendidos como todas as outras mercadorias, ou seja, seus preços de venda "são iguais aos elementos do custo (ao valor do capital constante e do capital variável consumido) mais um lucro, determinado pela taxa geral de lucro" (1986, p. 141). A questão proposta por Marx é como parte do lucro pode se transformar em renda fundiária e, assim, ir para o proprietário da terra.

A formação do preço das mercadorias não é determinada pelo custo de um produtor individual, mas pelo custo médio de produção de muitos produtores, logo, pelo mercado, independentemente de suas oscilações.

\footnotetext{
É da própria estrutura do preço de mercado e, além disso, da estrutura do preço regulador de mercado ou do preço de produção de mercado que a natureza do valor das mercadorias se coloque, que ela se determine não individualmente por meio do tempo de trabalho necessário para a produção de determinado quantum de mercadorias ou de mercadorias individuais, para determinado produtor individual, mas por meio do tempo de trabalho socialmente necessário: por meio do tempo de trabalho exigido para, nas condições sociais médias de produção, produzir o quantum global socialmente necessário das espécies de mercadorias encontráveis no mercado (MARX, 1986, p. 141-2).
}

ParaOnde!?, Porto Alegre, v.13, n.1, p.21-45, 2020. http://seer.ufrgs.br/paraonde 
Assim, quando um produtor consegue obter uma diferença entre o seu preço individual de produção e o preço social geral, regulador do mercado, este obterá um sobrelucro. Essa diferença é igual ao excedente do preço geral de produção da mercadoria sobre o preço individual (MARX, 1986, p. 142). Por fatores diferentes do capital e trabalho para a produção, por exemplo, fatores naturais, como a fertilidade do solo, a renda é gerada como a diferença entre o produto de quantidades iguais de capital e trabalho, "o sobrelucro se transforma em renda fundiária se duas quantidades iguais de capital e trabalho são empregadas com resultados desiguais em duas superfícies iguais" (MARX, 1986, p. 147).

Da mesma forma, a proximidade dos mercados locais, a melhor localização com os meios de transporte e comunicação, a composição química da superfície do solo são fatores que não resultam do trabalho individual, mas que favorecem o aparecimento da renda que é apropriada pelo proprietário da terra.

Quando o proprietário da terra é o próprio capitalista, a propriedade do solo não constitui uma barreira ao avanço do capitalismo e à valorização do capital, mas apenas um elemento da natureza. A barreira que a propriedade fundiária constitui desaparece para o investimento do capital. Por outro lado, quando se trata de pessoas diferentes, o proprietário da terra e o capitalista, o quadro é diferente. Para Marx a "propriedade fundiária sem o arrendamento nada vale, não tem economicamente valor", por isto tem que haver uma majoração nos preços de mercado, a fim de que novas terras possam ser incorporadas ao processo de produção. Esta elevação dos preços das mercadorias faz com que, além das terras de melhor qualidade, as terras menos férteis possam ser incorporadas ao processo produtivo. Como refere Marx,

Mas é como tal força estranha, como um obstáculo, que a propriedade fundiária se confronta com 0 capital em seus investimentos na terra, ou o proprietário da terra com o capitalista...

No entanto, devido à barreira que a propriedade fundiária coloca, o preço de mercado tem que subir até o ponto em que o solo pague um excedente acima do preço de produção, isto é, uma renda (1986, p. 228).

Uma vez que o valor das mercadorias produzidas pelo capital está acima de seu preço de produção, isto vai gerar uma renda, que constitui um excedente do valor sobre o preço de produção, que ainda será regulada pela relação da oferta e da demanda e da extensão do território incorporado ao cultivo. Ressalta Marx que, mesmo que a propriedade fundiária possa elevar o preço dos produtos agrícolas acima do seu preço de produção, isto não depende apenas da condição de propriedade, mas da situação geral do mercado, da capacidade do mercado absorver o preço das mercadorias. Isto faz com que novas terras, mesmo as menos férteis e mais distantes, sejam incorporadas ao processo produtivo, também gerando a possibilidade de obtenção de renda. Fora destas condições, Marx escreve que "a renda só pode basear-se num autêntico preço de monopólio, que não é determinado nem pelo preço de produção nem pelo valor das mercadorias, mas pela necessidade e pela capacidade de pagar dos compradores". Isto justifica a busca por novas terras dando direção aos movimentos populacionais.

Para0nde!?, Porto Alegre, v.13, n.1, p.21-45, 2020. http://seer.ufrgs.br/paraonde 
Karl Kautski, a partir deste estudo de Marx, relaciona este avanço sobre novas terras observando, por exemplo, a relação entre a fertilidade e a distância, bem como a necessidade de incorporação de novas terras. Sobre a diferença de fertilidade, escreve:

Inversamente, na agricultura, não são as despesas de produção necessárias num terreno médio que determinam o preço de custo. Quando, ao lado do melhor terreno, se cultiva um inferior, de superfície maior, não precisamos atribuir essa diferença, como já notamos, a circunstâncias extraordinárias ou a qualidades pessoais do agricultor. Isto acontece porque o terreno melhor não basta, por si só, a produzir os gêneros necessários para a subsistência da população. Mas o capitalista - trata-se aqui apenas da exploração capitalista do solo - exige da empresa a que se dedica, além do preço de custo, o lucro usual. O terreno inferior só será, pois, explorado por capitalistas se a insuficiência da oferta fizer subir os preços dos gêneros a tal ponto que mesmo a cultura desse terreno inferior renda bastante. Isto quer dizer que na agricultura não são as despesas de produção, necessárias para um terreno médio, mas as necessárias para o terreno pior, que determinam o preço de produção.

Destas duas diferenças entre a renda territorial e o lucro industrial resulta uma terceira. A população cresce, sobretudo, onde a indústria se desenvolve, e com ela aumenta a procura de gêneros alimentícios. Impõe-se o cultivo de novas terras. Mas por isso mesmo as diferenças de fertilidade entre as diversas zonas cultivadas aumentam no curso da evolução econômica e, por conseguinte, aumenta a renda fundiária (KAUTSKI, 1980, p. 89).

Já o desenvolvimento dos meios de comunicação e transportes aumenta a incorporação de terras mais distantes e distribui a possibilidade de obtenção de renda.

\begin{abstract}
Não são apenas as diferenças de fertilidade dos terrenos que constituem renda fundiária, mas ainda as diferenças de situação, a distância do mercado. Quanto mais a população de um centro aumenta e faz aumentar, no mesmo passo, a procura por gêneros no mercado, tanto maiores serão as distâncias em que estes poderão ser encontrados. Mas os terrenos mais distantes só são lavrados para o mercado no momento em que os preços dos gêneros sobem a tal ponto que cobrem, além das despesas de produção, as despesas de transporte, dando lucro médio ao capital. Disso resulta uma renda fundiária para os terrenos mais próximos ao mercado (KAUTSKI, 1980, p. 91).
\end{abstract}

Outra forma possível de aumento da referida renda são os melhoramentos em um terreno, como o melhoramento do solo, aplicando trabalho na forma de capital e salários, a fertilização através do uso de esterco, uso de instrumentos de produção; de forma que o cultivo de um terreno de pior qualidade, ao lavrar, possibilite um lucro extraordinário, resultando uma nova renda fundiária.

Todas são formas de rendas diferenciais, sejam as diferenças de fertilidade (naturais ou artificiais) ou as de situação dos terrenos. Na indústria é claro que este sobrelucro fica em poder do capitalista. Mas no campo isto acaba em boa parte em poder do proprietário fundiário. Quando o capitalista se torna ele o

Para0nde!?, Porto Alegre, v.13, n.1, p.21-45, 2020. http://seer.ufrgs.br/paraonde 
proprietário das terras, embolsa também o lucro extraordinário. Mas para isto vai ter que desembolsar uma parte do capital para a simples propriedade da terra e da renda nela contida. Caso contrário, vai ter que pagar o lucro extraordinário ao proprietário, mas apenas este, sob pena de não se viabilizar como um produtor capitalista. Assim, os terrenos piores ou mais distantes pagarão menos renda, tornando-se competitivos e atraentes ao capitalista. Em razão do solo não ser um bem multiplicável, a renda territorial, "uma parte do lucro extraordinário ficará nas mãos do arrendatário, realizará um lucro superior ao médio. A concorrência será assim atraída para esse lado, e ela fará subir o arrendamento", realimentando o processo (KAUTSKI, 1980, p. 95).

Outra consideração de Kautski sobre o lucro na agricultura é o fato de que o período de circulação do capital é particularmente longo. Isto impõe que no período de circulação do capital na agricultura, em média um ano ou uma safra, o capitalista tenha que calcular sua taxa de lucro total considerando o período total, sob pena de suprimir seu lucro extraordinário. Esta elevação pode vir da condição de monopólio da terra, aumentando os preços dos gêneros, dependendo apenas do campo de ação da lei de concorrência, seja interna ou externa. Quando os preços se elevam, retrai o círculo de consumidores, até que se veem obrigados a limitações. "Os senhores proprietários territoriais não podem, pois, fixar arbitrariamente o montante da renda fundiária absoluta. Dela retiram, porém, o máximo possível" (KAUTSKI, 1980, p. 97).

Kautski adverte que para uma pessoa embolsar uma renda territorial bastaIhe o título de proprietário fundiário, não havendo a necessidade de aplicação de trabalho para que isto ocorra. Contudo, definem os dois tipos de renda:

A renda diferencial resulta do caráter capitalista da produção, e não da propriedade privada do solo. Ela subsistiria se o solo fosse nacionalizado, como o desejam alguns partidários da reforma agrária, sob a condição de conservar-se a forma capitalista da exploração agrícola. Ela apenas não reverteria mais em benefício de particulares, mas da coletividade.

A renda territorial absoluta resulta da posse privada do solo e da oposição existente entre 0 interesse do proprietário fundiário e 0 interesse da coletividade. A nacionalização do solo suprimi-la-ia, reduzindo o preço dos produtos agrícolas.

Com efeito - e é esta a segunda distinção entre a renda diferencial e a renda absoluta - a primeira não constitui um fator que determine os preços dos produtos agrícolas, como a última. A primeira resulta dos preços de produção. A última provém do desvio entre os preços do mercado e os preços de produção. A primeira é constituída pelo excedente, pelo lucro extraordinário que o trabalho num solo melhor, ou de situação mais favorável, proporciona. A última, pelo contrário, não resulta de mais-valia realizada por certos serviços agrícolas. Ela só é possível, pois, mediante um desconto feito pelo proprietário territorial sobre os valores existentes, um desconto sobre a massa da mais-valia, uma diminuição, portanto, do lucro, ou desconto sobre o salário. Se os preços dos gêneros e os salários aumentam ao mesmo tempo, o lucro do capital diminui. Se os preços dos gêneros aumentam, sem que se verifique uma alta proporcional de salários, as vítimas serão os operários (KAUTSKI, 1980, p. 98-9). 
O limite da renda territorial absoluta é festejado pelo autor, na medida em que o fato da concorrência ultramarina atenuou a pressão exercida pelo aumento populacional na Europa. Sobre a ampliação das áreas cultivadas, nas palavras de Kautski (1980, p. 99), "continua-se a explorar, mesmo, a terra mais ingrata", bem como a intensidade, influenciando sobre o preço das mercadorias e mesmo o preço da terra. Mais adiante chama a atenção de que a terra não se constitui uma elaboração do trabalho humano, mas como se tornou uma mercadoria, seu preço não é determinado pelo trabalho necessário à sua produção, mas determinado pela renda territorial.

Como consequência, a elevação da renda territorial acontece após sucessivas fases de arrendamento, onde a disputa pelo uso da terra aumenta pela concorrência. Uma forma de amenizar a elevação do custo do arrendamento é aumentar o tempo deste. A partir daí se dá a compra efetiva da terra pelo arrendatário (lavrador), incorporando a renda territorial, mas imobilizando uma parte do seu capital produtivo. Isto somente poderá ser realizado pelo produtor com maior volume de capital, o que no processo favorece a formação e concentração de grandes proprietários. Mas como alerta Kautski (1980, p. 220):

O aumento do preço da terra constitui uma vantagem para os que deixam a agricultura e vendem as suas propriedades. Não constitui vantagem para os que se tornam lavradores, aos que compram ou herdam um domínio. Nada mais falso do que julgarmos de interesse da agricultura o aumento do preço do solo ou a sustentação de uma alta desse preço por métodos artificiais. Sê-lo-ão para os proprietários transitórios, para os bancos hipotecários, os especuladores de terras, mas não para a agricultura, e muito menos para o seu futuro, para a imediata geração de lavradores.

Em razão desta série de obstáculos ao desenvolvimento das relações capitalistas na agricultura, ou de sua racionalização através da intensificação da produção, a incorporação do solo vai se dando na medida em que existe a demanda por mais produção de mercadorias, que amplia o mercado e, consequentemente, a pressão da sociedade por mais terras, incorporando não só as terras boas, como as terras de pior qualidade ou mais distantes. $O$ próprio aumento do preço da terra tem seu limite, pois elevaria, também, o preço dos gêneros alimentícios, diminuindo o número de consumidores que não podem pagar tal preço. A consequência desta situação seria o aumento da emigração ou mortalidade, ou mesmo a diminuição da população e pressão pela terra. Por isto Kautski escreve que "os senhores proprietários territoriais não podem, pois, fixar arbitrariamente o montante da renda fundiária absoluta. Dela retiram, porém, o máximo possível" (1980, p. 96-7).

Outro limite descrito por Kautski à renda territorial absoluta é a possibilidade da concorrência de outros lugares mais distantes, na situação de uma elevação do preço das mercadorias, justificando a busca de alimentos "ultramarina". Esta possibilidade de concorrência na produção de mercadorias contribui para a formação do preço do solo, como nos descreve:

Sob o regime da propriedade privada do solo e da produção de mercadorias na agricultura, tornam-se mercadorias as próprias 
parcelas de terra. Quando os meios de produção se tornaram capital, foi-se levado a considerar o solo, também, como um capital. Ele não é. Por mais que se lhe dê continuamente o nome de capital, com isso não enriquece de um tostão o proprietário territorial. Sem dúvida, a sua terra se tornou uma mercadoria, que possui um preço e um valor comercial determinado. Mas esse valor obedece a leis diversas das que regulam o valor comercial comum. O solo não constitui uma elaboração do trabalho humano: o seu preço não é, portanto, determinado pelo trabalho necessário a sua produção. Muito menos pelas despesas de produção. Ele é determinado pela renda territorial. $\mathrm{Na}$ sociedade capitalista, o valor de uma parcela de chão ou de um bem se assemelha ao valor de um capital cujo rendimento fosse igual ao montante da renda fundiária do solo em apreço. O valor desse capital é o valor comercial da terra. Este é, pois, determinado de um lado pelo montante da renda fundiária de outro pela taxa usual de juro (KAUTSKI, 1980, p. 100).

Portanto, mesmo em áreas mais distantes, é necessária a densidade demográfica para que o preço do solo não caia de forma a prejudicar os negócios capitalistas. O seja, é preciso que haja necessidade social da terra para que alcance um preço de mercadoria. Isso ajuda a explicar a convivência entre grandes e pequenos proprietários lado a lado.

\section{A produção familiar e a renda}

Antes de tratar do tema produção familiar e renda a partir de uma breve análise de Alexander Chayanov, vamos destacar o comportamento particular do campesinato e a formação de preços das mercadorias, ou seja, formas não capitalistas de produção, mas que estão no caminho da incorporação capitalista da terra. Como as demais formas de produção na agricultura, a unidade de produção familiar camponesa tem particularidades por um funcionamento interno, que a diferencia das demais formas de produção capitalista. Para Wanderley (2014, p. 141): "É Chayanov quem elabora uma proposta teórica original de compreensão dos processos internos de funcionamento das unidades familiares de produção na agricultura". Chayanov aborda justamente aquela parcela da produção agrícola que difere da produção capitalista, ou seja, a exploração do trabalho familiar sem assalariados.

Basicamente, o centro desta diferenciação proposta por Chayanov pode ser compreendido na citação abaixo:

A teoria econômica da sociedade capitalista moderna é um sistema complexo de categorias econômicas - preço, capital, salários, juro, renda -, todas elas estreitamente ligadas umas às outras, determinando-se mutuamente e funcionalmente interdependentes. Se tirar uma pedra desta construção, todo o edifício desmorona... Por exemplo, não pode se aplicar, com o seu sentido habitual, qualquer das categorias econômicas enumeradas a uma estrutura econômica destituída de preço, isto é, um sistema completo de unidades funcionando em economia natural e servindo exclusivamente para satisfazer as necessidades das famílias de trabalhadores ou outras comunidades. Em economia natural, a atividade econômica humana é 
dominada pela satisfação das necessidades de cada unidade de produção isolada - a qual é, ao mesmo tempo, uma unidade de consumo. Assim, a preparação de um orçamento é aqui, em larga medida, qualitativa: para cada necessidade da família tem de ser fornecido, em cada unidade econômica, o produto qualitativamente correspondente em gêneros (CHAYANOV, 2014, p. 103).

O autor salienta que a decisão de cada unidade de produção é qualitativamente distinta, particular, segundo as necessidades da família. Ao colocar em ação sua força de trabalho familiar, equipada de meios de produção para cultivar o solo, é possível se verificar a inexistência da categoria salário, bem como do lucro, da renda, dos juros ou do capital.

Este produto do trabalho familiar é a única categoria possível de rendimento para uma exploração artesanal ou camponesa baseada no trabalho familiar, visto não existir maneira de decompor analítica e objetivamente o rendimento. Posto que o fenômeno social do salário não existe, também não existe o fenômeno social do lucro líquido. É, portanto, impossível aplicar o cálculo capitalista do lucro (CHAYANOV, 2014, p. 105).

Sobre esta particularidade do "produto indivisível do trabalho", segue Chayanov (2014, p. 15):

\begin{abstract}
Haverá variações segundo a situação do mercado, a localização da exploração relativamente aos mercados, as disponibilidades em matéria de fatores de produção, a dimensão e a composição da família, a qualidade do solo, assim como todas as outras condições de produção próprias à exploração. Porém, como veremos mais adiante, o excedente obtido pela exploração devido a uma melhor localização, ou as disponibilidades relativamente melhores em matéria de fatores de produção, não é idêntico nem em quantidade à renda ou ao juro do capital na economia capitalista.
\end{abstract}

Por outro lado, a composição da família é importante pela definição do número de pessoas, sexo, idade, o que resulta na força de trabalho, bem como a consequente transformação do trabalho em produtos para consumo próprio e o excedente a ser comercializado. Sobre este recai o fator localização em relação ao mercado. A facilidade ou dificuldade em comercializar o excedente contribui para a diferenciação entre os produtores, que, somada à composição da família, ou capacidade de autoexploração, possibilita a acumulação de uns produtores ser diferente da dos outros. Sobre esta forma de exploração contribuem, também, os fatores naturais de diferenciação, como a qualidade do solo ou suas características quanto ao tipo de relevo, vegetação e disponibilidade de água no terreno.

No caso da unidade familiar, estes fatores naturais ou sociais diferenciadores das unidades de produção estão internos à unidade de produção, dispostos em uma relação de equilíbrio entre a satisfação das necessidades da família e a fadiga em relação ao trabalho (limite da capacidade de trabalho em uma unidade de produção familiar).

A importância do produto do trabalho é principalmente determinada pela dimensão e composição da família, ou seja, o número de pessoas da família capazes de trabalhar pela produtividade da

Para0nde!?, Porto Alegre, v.13, n.1, p.21-45, 2020. http://seer.ufrgs.br/paraonde 
exploração e - o que é particularmente importante - pelo grau de autoexploração, graças ao qual os ativos fornecem uma certa prestação de trabalho ao longo do ano.

Minuciosos estudos empíricos relativos às explorações camponesas da Rússia e de outros países nos permitiram verificar a seguinte tese: o grau de autoexploração é determinado por um equilíbrio específico entre a satisfação da procura familiar e a fadiga devida ao trabalho (CHAYANOV, 2014, p. 106).

O que define o que e o quanto é necessário para a satisfação das necessidades da família é a sua composição. Uma família mais jovem com filhos pequenos é diferente de outra com maior número de pessoas com diferentes idades, jovens ou idosos. O número de pessoas dentro de uma unidade de produção pressiona para a necessidade de aquisição de mais terras, ou isto levará à necessidade de emigração de parte de seus membros. Em uma população camponesa, quando este excedente populacional aparece em várias unidades familiares, este passa a ser um dos principais fatores de elevação do preço da terra, um fator interno, portanto. "Concluindo, temos de considerar que o preço da terra, enquanto categoria objetiva, depende de uma dada situação do mercado fundiário, isto é, da importância e da urgência da procura pela terra por parte dos camponeses com pouca terra e da oferta disponível por qualquer razão" (CHAYANOV, 2014, p. 112).

Tudo gira em torno do equilíbrio das necessidades familiares e do consumo, que resulta em uma determinada quantidade de trabalho por parte dos membros da família em condição de exercer tal atividade. O limite é dado pela fadiga para se atingir o objetivo da necessidade. Para o autor, uma vez atingido o objetivo, as necessidades da família deixam de fazer sentido à continuidade do trabalho. O aumento da produtividade diminui o esforço no sentido de atingir o objetivo da satisfação. Quando uma família estiver mais sobrecarregada de pessoas incapazes de trabalhar terá que intensificar a autoexploração da força de trabalho familiar. Por esta razão, cada unidade econômica terá que realizar o cálculo objetivo de suas necessidades, a partir de avaliações subjetivas do que deve ser alcançado.

Diferentemente, uma economia capitalista somente vai aumentar ou reduzir sua capacidade de trabalho em função da avaliação do mercado, o que deslocará sua capacidade produtiva para o aumento ou a redução da produção, bem como os investimentos a serem realizados. Ao contrário, na economia familiar, as decisões de aumento ou redução da produção levam em conta uma relação desfavorável entre o tamanho/composição da família e a superfície a ser cultivada.

Assim, as avaliações subjetivas são internas à unidade de produção, naquilo que a família entende como necessidades aceitáveis. Por isto é que o produto interno do resultado do trabalho será indivisível, pois é o fruto do somatório do trabalho familiar que visa à satisfação de todos os membros: crianças, jovens, adultos e idosos.

Disto resulta um comportamento econômico interessante: a inelasticidade da oferta. A produção é determinada fundamentalmente pelos fatores internos à unidade familiar, não se alterando de forma significante às variações de preço

Para0nde!?, Porto Alegre, v.13, n.1, p.21-45, 2020. http://seer.ufrgs.br/paraonde 
do mercado. O que determina o tamanho da produção é a relação entre a capacidade de trabalho e a satisfação da família, por um lado, e a fadiga, por outro.

Como a comercialização da produção familiar é regulada pelo mercado do tipo "oferta e procura", acaba o produtor na seguinte situação: se produz muito, resultado de condições naturais e sociais favoráveis, o volume de produtos ofertados leva à queda do preço do produto. Em situação oposta, quando os fatores desfavoráveis diminuem a oferta destes, o preço sobe, mas há poucos produtos a ofertar.

Um importante exemplo desta situação é trabalhado por Martins (1975) na importante obra Capitalismo e Tradicionalismo, no capítulo Modernização Agrária e Industrialização no Brasil, onde a produção de leite é analisada na montanha e na planície no Vale do Paraíba. Na montanha o leite é vendido a preços inferiores aos praticados na planície, dando-lhe condições de se inserir no mercado. Na planície o leite é resultado da especialização da produção, onde a terra é utilizada com vistas ao mercado. Na montanha o leite está junto com a produção de outros artigos que compõem a subsistência da própria população rural, como a produção de feijão. Na planície os outros artigos para a subsistência são comprados com o dinheiro da venda do leite.

Desta maneira, a produção de leite, ainda que mais intensiva, tem um custo de produção maior que o leite produzido na montanha. Por isto o leite produzido na montanha, embora mais distante e com custo de transporte maior, pode ser vendido a qualquer preço, e o da planície não. Isso vai se refletir sobre o modo de vida na montanha e a sua relação com o mercado, como descreve a respeito da economia baseada no excedente:

Neste sentido, a população rural da montanha organiza a sua produção de conformidade com 0 padrão tradicionalmente estabelecido, preservando instituições tradicionais, como o mutirão, as festas propiciatórias no fim do ano agrícola e antes do plantio dos artigos essenciais da sua dieta alimentar, etc. Mantendo, enfim, os costumes na organização da cultura, da sociedade e da economia e rebatendo para um plano muitas vezes tangencial os efeitos da participação em uma economia monetária.

O leite, pois, não obstante ser consumido e comercializado nas mesmas proporções na planície e na montanha, é excedente na segunda e não o é na primeira. $O$ excedente não é o produto que sobra do consumo, mas o produto dos fatores de produção excedentes que foram utilizados na subsistência (no caso, a mão de obra e a terra com as suas pastagens naturais). É o fator excedente que gera o produto excedente e que define a economia, a sociedade e a cultura baseadas no excedente, à margem das relações monetárias, das relações sociais abstratas, da dominação política, das relações capitalistas de produção típica, da conduta racional com relação a fins seculares (MARTINS, 1975, p. 12).

O leite na montanha é produzido pelo trabalho familiar, nos moldes colocados por Chayanov, um produto indivisível do trabalho na unidade de produção familiar. Portanto, a venda do leite como mercadoria excedente pode ser realizada a qualquer preço, pois não está sendo remunerada uma parte do trabalho da família ou da renda da terra ao seu proprietário. O preço do leite na

Para0nde!?, Porto Alegre, v.13, n.1, p.21-45, 2020. http://seer.ufrgs.br/paraonde 
planície, fruto do investimento e da especialização da produção, ainda que com mais produtividade e estabilidade de oferta, tem que remunerar o capital investido, trabalho e renda da terra. Isto difere quanto à inelasticidade da oferta na montanha e a variação da oferta da produção de leite na planície. $\mathrm{Na}$ planície a produção de leite obedece a outros critérios, entre eles, talvez 0 principal, o trabalho assalariado e o investimento nos meios de produção.

A resposta ao mercado marca a diferença de produção, ou seja, toda vez que o preço do leite sobe, a produção capitalista na planície aumenta e atende a demanda na cidade, diminuindo a procura na montanha. Por outro lado, quando cai o preço do leite, diminui a produção na planície, aumentando a procura pelo produto na montanha, ou seja, os atravessadores buscam na produção familiar o abastecimento do leite na cidade.

Outro exemplo que descreve a produção familiar e renda é o analisado por Leo Waibel, em seu livro Capítulos de Geografia Tropical e do Brasil, quando analisa os Princípios da Colonização Europeia no Sul do Brasil, em especial os camponeses de descendência alemã no estado do Rio Grande do Sul. A respeito do tamanho das propriedades, Waibel se surpreende que a maioria dos colonos e agrônomos da época aceitasse que o tamanho médio das propriedades de um colono da mata fosse de 25 a 30 hectares. Argumentava 0 geógrafo que esse tamanho era excessivamente pequeno para regiões montanhosas. Que um processo de colonização deveria ser estudado de todos os ângulos, "principalmente à mínima quantidade de terra necessária para proporcionar a um agricultor e sua família um padrão econômico e cultural decente", definido pelo autor pela expressão Minimale Ackernahrung (WAIBEL, 1958, p. 240). Portanto, uma parcela mínima de terras para um colono e sua família aplicarem o sistema de rotação de terras.

Não se trata neste texto de discutir o tamanho mínimo da parcela, mas da possibilidade do agricultor realizar a rotação de terras e evoluir de um sistema de produção para outro, a saber:

a) sistema de rotação de terras primitivas: sistema herdado do caboclo (lavrador nacional), que consistia na derrubada da mata e no cultivo de milho, feijão e mandioca usando uma cavadeira e enxada primitivas;

b) sistema de rotação de terras melhoradas: depois que a mata foi devastada e que a densidade da população aumentou com o auxílio das estradas, foi possível introduzir outros tipos de cultivo, como a batata inglesa, o trigo e o centeio no inverno, e o arroz no verão. Nos cruzamentos das estradas começaram a se estabelecer os moinhos de famílias de antigos comerciantes. O desenvolvimento da pecuária de suínos e aves acarretou uma aceleração nas atividades da região colonial, que trocou os seus produtos com as cidades maiores, de origem lusa, que sofriam com o desabastecimento;

c) sistema de rotação de culturas combinada com a criação de gado: com as terras aradas com tração animal, alguns colonos conseguiram associar a lavoura à criação de gado, o que ajudava na adubação da terra, permitindo a alternância de cultivos de cereais com cultivos de raízes e leguminosas para enriquecer o solo com nitrogênio.

Para0nde!?, Porto Alegre, v.13, n.1, p.21-45, 2020. http://seer.ufrgs.br/paraonde 
Entretanto, segundo Waibel (1958, p. 226-241), nem todos os colonos tiveram a mesma oportunidade de produzir suas terras em condições adequadas. Na busca pela sobrevivência, muitos colonos não desenvolveram os três estágios de sistemas de uso da terra, aumentando os fatores de diferenciação dos camponeses, como aqueles já descritos por Chayanov. A impossibilidade econômica de criação pecuária bovina, com a finalidade de produzir esterco para a adubação, não permitiu a adubação da terra de forma tradicional, devido à concorrência com esta atividade nos campos ao sul, onde a cultura da produção e os campos favoráveis deslocavam a concorrência a favor dos estancieiros sulistas.

A utilização de terras muito inclinadas, provocando erosão do solo, somada à distância e ao isolamento de muitos agricultores, levou à deterioração do solo e à sua exaustão. Como coloca Waibel (1958, p. 233):

\begin{abstract}
A maioria das colônias do planalto do Rio Grande do Sul está nesta condição deplorável. A primeira geração de colonos que devastou as matas no decênio de 1890, e, que, depois de alguns anos de pioneirismo, estabeleceu o sistema de rotação de terras melhoradas, tornou-se logo próspera e constituiu boas propriedades. A segunda geração aplicou as mesmas práticas agrícolas, daí resultando que os seus padrões econômicos baixaram consideravelmente, e a terceira geração, ou teve que se mudar para outro lugar, ou se tornou cabocla. O número de caboclos europeus é surpreendentemente elevado, mesmo em colônias que há 25 anos eram consideradas colônias-modelos.
\end{abstract}

Waibel usa o termo caboclo como sinônimo de lavrador nacional, ou aqueles que não tiveram acesso à terra como mercadoria e, por conseguinte, à propriedade privada do lote para cultivar, a exemplo dos negros, índios e mestiços. O sistema utilizado pelos lavradores nacionais era o sistema de rotação de terras primitivas. Na impossibilidade de evoluir para os demais sistemas mais complexos acima descritos, diz Waibel que os camponeses se "acaboclaram", como segue o texto:

Os pequenos proprietários europeus não poderiam aplicar, por gerações sucessivas, o sistema agrícola mais extensivo e mais primitivo do mundo sem abrir mão e perder elementos essenciais da cultura e tradição. Especialmente nas áreas montanhosas, de povoamento antigo e nas regiões remotas, muitos colonos alemães, italianos, polacos e ucranianos tornaram-se verdadeiros "caboclos", gente extremamente pobre, com muito pouca ou nenhuma educação e vivendo nas casas mais primitivas. Estas áreas estão a grandes distâncias das estradas de ferro e das modernas rodovias, e não são visitadas pelo turista ou viajante comum (WAIBEL, 1958, p. 227).

Esta separação da lavoura e da atividade pecuária bovina de corte é, para o autor, um dos problemas da produção de alimentos no Brasil em sua época, conforme segue:

A ausência deste sistema de associação lavoura-pecuária é o fato fundamental da vida econômica do Brasil, bem como de todos os outros países dos trópicos americanos. Aí, os dois principais ramos da agricultura estão separados, tanto econômica quanto espacialmente. Isto leva, por um lado, ao primitivo sistema de rotação 
de terras, e por outro, ao igualmente primitivo sistema de pastoreio em grandes fazendas. Desta maneira, o Brasil tem desperdiçado e perdido o fertilizante mais valioso, o estrume, e os seus solos têm deteriorado a tal ponto que têm causado alarme aos agricultores assim como os estadistas.

De acordo com a lei de Von Thünen, a pecuária isolada sob a forma de pastoreio é economicamente sadia e justificada a grande distância do mercado. Encontramo-la, portanto, nas áreas remotas de muitos países. À semelhante distância do mercado, o clima seco favorece a separação econômica entre a lavoura e a criação de gado. No Brasil, entretanto, a pecuária sob a forma de pastoreio em grandes fazendas ocorre não somente no interior longínquo e no nordeste semiárido, mas também nas terras úmidas outrora florestais, ao longo da costa marítima. O sertão litorâneo, ou deserto demográfico ao longo da costa, é um aspecto tipicamente brasileiro, que não encontramos em nenhum outro grande país do mundo. E a horrível tríade cultural do Brasil: falta de alimentos, subnutrição e pobreza da população, estão basicamente relacionadas com a separação econômica e espacial da agricultura e da pecuária (WAIBEL, 1958, p. 255).

Frente às dificuldades nas áreas montanhosas, devido ao lote ser demasiado pequeno para desenvolver o primeiro sistema e passar para o segundo, longe das estradas e da atividade do comércio, bem como do colégio para os filhos, alguns lavradores ficaram reféns dos comerciantes, seu único contato com o mundo distante e que enriqueceram às suas custas. O projeto de colonização, segundo Waibel, não observou o que chamou de Minimale Ackernahrung, ou seja, uma quantidade mínima de terra para garantir um bom padrão de vida para o agricultor. Consequentemente, aqueles colonos que não conseguiram sair do primeiro estágio migraram para a fronteira agrícola, abandonando ou vendendo seus lotes. Waibel entendia que os lotes deveriam ter entre 55 e 65 ha em terra considerada de boa qualidade, e de 85 a 105 ha em terra ruim.

Diante dessa situação, muitos filhos de colonos europeus pobres, considerados caboclos a partir de então, partiram para a cidade ou em busca de novas terras na direção do oeste catarinense e da região Centro-Oeste. Ao contrário, aqueles que conseguiram diversificar na lavoura e no comércio acumularam riquezas e também diversificaram atividades comerciais nas cidades coloniais que cresciam economicamente. Este sujeito com capital disponível e com tradição agrícola estava pronto para a produção e reprodução das relações sociais capitalistas na região do Planalto Meridional do Rio Grande do Sul (AUTOR, 2011, p. 137).

Um terceiro e último exemplo que diz respeito à produção de cebolas em agricultura familiar foi estudado no município de São José do Norte entre os anos de 1990-94. Neste momento a produção sofria concorrência de outras regiões, mas principalmente do estado de Santa Catarina, que nesta época já contava com maior produção e produtividade, substituindo a liderança nacional ocupada por décadas pelos produtores nortenses. Devido ao isolamento e às péssimas condições da estrada RST 101, por um lado, e à precária ligação lagunar com a cidade de Rio Grande por balsa, por outro, o único produto comercializável pela população camponesa era a cebola. Nos moldes chayanovianos, o comportamento de produção de excedentes era notável, pois 
os próprios agricultores admitiam que o único produto que "dava" naquele lugar era a cebola, ainda que por insistência do pesquisador, mas na horta se produzia de tudo, como descrito por AUTOR (2009).

Entretanto, o escoamento diário de uma variedade de produtos era praticamente impossível, devido às péssimas condições de trafegabilidade da estrada. Havia pouco dinheiro circulando no interior do município, mas não havia miséria ou fome. Ao contrário, havia uma intensa solidariedade entre a população no sentido de troca de trabalho (mutirão), alimentos (carnes e vegetais) e mesmo empréstimos de ferramentas e terra para plantio. Porém, o único produto que poderia se tornar mercadoria era a cebola, porque na época da sua safra os produtores comerciantes, com estabelecimentos próximos à sede municipal, compravam-na dos produtores do interior, revendendo-as para outros compradores externos, como paulistas e pernambucanos. Em outras palavras, os "atravessadores" locais faziam a comunicação entre os produtores camponeses interioranos do município e os grandes atacadistas do centro do país.

Os produtores nortenses chegaram a ter períodos onde a comercialização de excedentes (cebola) garantiu boas condições de aquisição de bens necessários à reprodução da família, sempre seguindo a lógica da composição da família (quantidade de trabalho e disponibilidade de terras) e da inelasticidade da oferta. Ao contrário, quando o preço da cebola não pagava nem o transporte até a sede municipal, o produto era jogado na estrada ou servia de alimentação para a pecuária bovina.

Entretanto, em meados da década de 1980, os produtores familiares catarinenses trocaram a produção de fumo pela produção de cebolas, resultado de um programa estadual de reconversão produtiva, e, mais tecnificados pela exigência da fumicultura, rapidamente ofertaram o mesmo produto que os produtores nortenses, em maior quantidade e mais próximo dos centros consumidores do Centro e Nordeste do país. E, principalmente, nos mesmos meses de verão. Os compradores nacionais passaram a se interessar pelo produto gaúcho apenas quando o mesmo produto catarinense apresentava um custo muito superior, compensando o deslocamento até São José do Norte.

Desta forma, o preço da cebola nortense não mais recuperou as altas de preços, como em situações passadas, desestimulando a produção de cebolas e desmontando a base de produção familiar. Durante a década de 1990, a maior parte da população rural se tornou urbana, por falta do que trocar e estimulada pela aposentadoria rural, que igualou os direitos previdenciários urbanos e rurais (SANTOS, 2009).

A produção familiar ou camponesa tem transferido riqueza em forma de trabalho e renda para outros setores ao longo do tempo e sempre nos lugares mais distantes, ou com mais obstáculos à produção e/ou escoamento, e, via de regra, em produtos da alimentação básica dos consumidores urbanos. 


\title{
4. A produção, a renda da terra e o modo de vida
}

Retomando a questão da renda da terra, Martins (1986, p. 161) ressalta que no avanço das relações capitalistas no campo, a terra se põe como um obstáculo, pois a licença para a exploração capitalista da terra depende de um pagamento ao seu proprietário: "esse pagamento é a renda da terra". Todavia, a renda não deve ser confundida com 0 aluguel, que expressa a renda territorial em algumas circunstâncias. Contudo, a renda fundiária existe mesmo onde não exista o pagamento do aluguel.

Quando o capitalista compra a terra está imobilizando uma parte do seu capital produtivo - para gerar mais-valia - em renda, renda capitalizada, mas está pagando pela utilização da terra. Renda capitalizada não é capital. Portanto, nem toda produção agrícola pode interessar ao capital, apenas os produtos que na venda realizem o pagamento do capital investido, ou seja, a reposição mais o lucro médio da atividade capitalista em seu tempo. Onde a produção capitalista não encontra estas condições, como na produção de alimentos que vão onerar a força de trabalho, vai criar as condições para oportunizar a transferência desta renda para o capital, através do não pagamento do trabalho ou da renda, como no caso da produção familiar analisada nos exemplos citados. Desta forma, segue:

\begin{abstract}
No Brasil, o movimento do capital não opera, de modo geral, no sentido da separação entre a propriedade e a exploração dessa propriedade, no sentido da separação entre o burguês e o proletário. O que vemos claramente, tanto no caso da grande propriedade quanto no caso da pequena, é que fundamentalmente o capital tende a se apropriar da renda da terra. O capital tem se apropriado diretamente de grandes propriedades ou promovido a sua formação em setores econômicos do campo em que a renda é alta, como no caso da cana, da soja, da pecuária de corte. Onde a renda é baixa, como no caso dos alimentos de consumo interno generalizado, como os que foram indicados, o capital não se torna proprietário da terra, mas cria as condições para extrair o excedente econômico, ou seja, especificamente renda onde ela aparentemente não existe (MARTINS, 1986, p. 175).
\end{abstract}

De uma forma geral, nos cultivos onde é possível a mecanização, como soja, arroz, cerais, entre outros, bem como a associação da pecuária bovina com a lavoura, a renda da terra é alta, pois além de condições naturais e sociais, distância, infraestrutura, existe a possibilidade de apropriação de maisvalia em função da exploração do trabalho. Nesse caso, a forma mais encontrada de trabalho será o assalariamento da força de trabalho.

Já os produtos de consumo interno generalizado, ou de alimentos a exemplo do feijão, milho, mandioca, uva, entre outros, se dão em regiões de difícil mecanização, onde a mão de obra é mais utilizada. Nestes casos, as formas de trabalho são a parceria, o trabalho familiar, a integração com a indústria e pouco assalariamento, mas nunca como forma preferencial.

Quanto mais nos afastamos para o passado mais vemos este tipo de transferência. A necessidade de produção de alimentos para uma população

Para0nde!?, Porto Alegre, v.13, n.1, p.21-45, 2020. http://seer.ufrgs.br/paraonde 
urbana em crescimento e com maior poder aquisitivo criou as condições de novos tipos de transferência, como a integração com a indústria e o produtor familiar. Em consequência, ocorreram especializações regionais na forma de integração entre produtor e empresa capitalista.

A partir de meados dos anos 1990, principalmente nos anos 2000, intensificou-se a elevação do patamar tecnológico nas unidades de produção de base familiar através do Programa Nacional de Fortalecimento da Agricultura Familiar (Pronaf), o que, além de tecnificar a produção, produziu um efeito de especialização desta, bem como da racionalidade da empresa familiar, aumento da necessidade de assalariamento em algumas etapas, da produção intensiva, aproximando ainda mais o produtor da integração com a agroindústria. Em alguns casos, como a agricultura orgânica, vinhos, leite e seus derivados, entre outros, adotou-se uma nova regionalização, mais de acordo com o nível de consumo urbano, o conceito de terroir, que significa um produto diferenciado, resultado do somatório de características regionais, como o clima, e de conhecimentos acumulados pela comunidade agrícola ao longo do tempo.

Como no caso da produção vinícola, para exemplificar apenas este caso, uma zona de certificação de origem pode diferenciar o consumo do produto entre o popular e o sofisticado no consumo urbano. Não está em jogo apenas a qualidade da confecção do produto, mas da forma e do pertencimento do segmento social que consome o produto, contribuindo para a formação da identidade social de quem consome. Para um mesmo produto, o vinho, em zonas certificadas, um produtor pode acrescer ganhos espetaculares em relação a outro produtor de zonas não certificadas. Este é um elemento a mais no debate sobre renda fundiária, pois a criação destas zonas de certificação de origem tem uma forte contribuição urbana, desde a criação dos critérios de sua formação, impregnada de fatores geográficos, até o despertar do desejo de consumo em seu público preferencial, dotado de um poder de consumo elevado.

Esta aproximação e especialização com a indústria por produtores agrícolas, mais tecnificados e com a exigência de uma racionalidade voltada para 0 investimento e o lucro, não descaracteriza a produção familiar, muitas vezes a base da formação do terroir. Entretanto, isso aproxima os produtores agrícolas das relações de produção capitalista, diferentemente de produtores familiares, que não conseguem se inserir neste processo, seja por fatores como distância, características do terreno ou mesmo incapacidade de leitura de uma produção com uma racionalidade diferente daquela a que está acostumado.

Aliás, sobre o pensamento dualista latifúndio-minifúndio, capitalistacamponês ou grande-pequeno agricultor, é bom que se avalie que a racionalidade empresarial, voltada em meios e fins para a obtenção do lucro, resulta do uso intensivo dos fatores de produção, e não do tamanho da unidade de produção ou propriedade. É o uso da técnica e da qualidade do trabalho que proporciona as condições de uso do trabalho assalariado, não o tamanho, como descreve Lênin (1980, 62-3):

A agricultura europeia se desenvolve, sobretudo sob a forma

Para0nde!?, Porto Alegre, v.13, n.1, p.21-45, 2020. http://seer.ufrgs.br/paraonde 
intensiva, não pelo crescimento da quantidade de terra cultivada, mas pela qualidade do trabalho e da terra, pelo aumento do capital investido. E é esta via fundamental do desenvolvimento da agricultura capitalista (que se torna, gradualmente, também a americana) que perdem de vista aqueles que se limitam a comparar as explorações unicamente de acordo com a sua superfície.

A via fundamental do desenvolvimento da agricultura capitalista consiste precisamente em que a pequena exploração, permanecendo pequena pela extensão de terra, transforma-se em grande exploração pelo volume da produção, desenvolvimento da pecuária, quantidade de adubos utilizados, desenvolvimento do emprego de máquinas, etc.

Portanto, é absolutamente falso concluir, após uma comparação das explorações agrupadas segundo a sua superfície, que à medida que a exploração cresce em dimensão, a agricultura torna-se menos intensiva. Ao contrário, a única conclusão correta é aquela a que se chega quando se comparam as explorações segundo o valor de seus produtos: à medida que a exploração ganha em magnitude, a agricultura torna-se mais intensiva... Quando se fala da pequena agricultura, pensa-se naquela que não repousa no trabalho assalariado. Ora, a passagem à exploração de trabalhadores assalariados está condicionada não apenas pela extensão da unidade agrícola, conservando-se a sua antiga base técnica (o que só ocorre numa economia extensiva, primitiva), mas também pelo aperfeiçoamento e modernização da técnica, pela aplicação numa mesma superfície de terreno de um capital suplementar sob a mesma forma, por exemplo, de novas máquinas ou de adubos artificiais, ou do aumento e melhoria do gado, etc.

O assalariamento não passa, necessariamente, pela ordem de grandeza, mas pela base técnica e intensidade de trabalho por área. Esta interpretação da realidade da pequena produção é fundamental nos dias de hoje, visto que a integração com a agroindústria possibilita, tanto ao produtor quanto à indústria, ganhos especiais que se baseiam em produtos que apelam para o produzido espacialmente para você: consumidor. O resultado da implementação da técnica às unidades de produção menores não descaracteriza a produção familiar, mas certamente a coloca em situação diferente daquela do campesinato chayanovista, onde a renda da terra é baixa. Esta forma de produção familiar moderna não é necessariamente adepta da Revolução Verde, mas é tecnicamente mais avançada, com sua produtividade intensiva, com períodos de trabalho assalariado, com diferentes expectativas para os filhos, estes já integrados em uma nova e mais estreita relação campo-cidade.

Frente a uma nova situação do trabalho e vida no meio rural, propomos uma interpretação do avanço do capitalismo no campo, segundo a condição da renda fundiária, que possibilita diferentes composições de capital, como um gradiente entre a empresa tipicamente capitalista e o camponês descrito por Chayanov. Naquelas situações em que a renda é baixa para uma atividade capitalista, no sentido em que há capacidade de gerar lucro, mas existe a demanda pela população, o capital criará as condições necessárias para se associar com produtores para deles extrair o produto da terra, sem o total pagamento da renda, tanto da terra como do trabalho, através do pagamento do produto, e não do trabalho necessário para a realização do produto.

Para0nde!?, Porto Alegre, v.13, n.1, p.21-45, 2020. http://seer.ufrgs.br/paraonde 
Quadro 1. Especialização da produção agrícola e fatores de modernização.

\begin{tabular}{|c|c|c|c|}
\hline \multicolumn{4}{|c|}{ QUADRO DE MODERNIZAÇÃO NO CAMPO } \\
\hline + Urbano & & & + Rural \\
\hline + Renda fundiária & & & - Renda fundiária \\
\hline + Capitalista & & & + Trabalho familiar \\
\hline Empresa rural & \multicolumn{2}{|c|}{ Integrados } & Camponês \\
\hline & \multicolumn{2}{|c|}{ Produtos } & \\
\hline Arroz & Uva & Batatas & $\begin{array}{l}\text { Produção } \\
\text { excedente }\end{array}$ \\
\hline Soja & Leite & Cebola & \\
\hline Trigo & Frango & Feijão & \\
\hline Pecuária empresarial & Suíno & Milho & \\
\hline \multirow[t]{2}{*}{ Cereais } & Fumo & & \\
\hline & Hortigranjeiros & & \\
\hline + Infraestrutura & & - Infraestrutura \\
\hline + Especialização & & & - Especialização \\
\hline \multirow[t]{3}{*}{ + Crédito/Subsídio } & \multirow{3}{*}{\multicolumn{2}{|c|}{$\begin{array}{l}\text { + Possibilidade de pluriatividade - } \\
\text { + Integração campo-cidade - }\end{array}$}} & - Crédito/Subsídio \\
\hline & & & \\
\hline & & & \\
\hline
\end{tabular}

A empresa rural representa a atividade capitalista por excelência, com uma racionalidade e organização do trabalho voltadas para o lucro. O trabalho assalariado ocorre com frequência sazonal, tendo um número maior de trabalhadores temporários que de permanentes. A renda fundiária é mais alta, a produção cada vez mais capitalizada, necessitando para sua obtenção do lucro toda a infraestrutura colocada pelo Estado, desde, pelo menos, a implantação do Estatuto da Terra, de 1964. A agricultura de precisão nada mais é que a elevação da renda diferencial na totalidade do lote explorado, ou seja, a padronização da maior rentabilidade possível por área, a produtividade diferencial, o que propicia a acumulação da renda diferencial ao produtor capitalista.

Do outro lado do quadro está presente o camponês produtor de excedentes, aquele que produz a qualquer preço, visto que não ocorre investimento na produção, e que responde pelo abastecimento cada vez mais ocasional. No atual momento estes produtores só podem ser encontrados em áreas isoladas, de difícil acesso, despovoadas pela emigração dos jovens e dos produtores aposentados que foram para as cidades (processo de taperização). Ou seja, onde a renda da terra é mais baixa e com obstáculos à instalação de associações com empresas capitalistas.

Em diferentes graus de capitalização e especialização se encontram os produtores integrados, onde os fatores como a distância dos centros urbanos e associação com o capital (agroindústria) colaboram para maior diferenciação ou não. A produção de fumo ou uva, por exemplo, pode incluir uma unidade de produção familiar que cultive fumo de forma orgânica, como estudado por Dutra (2015) no município de Canguçu, ou do terroir da uva por Falcade (2011) nos municípios da Serra gaúcha, o que coloca estes produtores em uma condição

Para0nde!?, Porto Alegre, v.13, n.1, p.21-45, 2020. http://seer.ufrgs.br/paraonde 
de especialização e remuneração pelo produto diferenciada em relação aos outros produtores familiares.

A condição de proximidade com a cidade possibilita uma série de oportunidades ao pequeno produtor rural. A pluriatividade - como a busca de formas alternativas para garantir a reprodução das famílias de agricultores não é apenas uma determinação do trabalhador, ou uma vontade ou um desejo seu, mas também uma condição espacial. Queremos dizer com isto que não há a possibilidade da pluriatividade sem uma proximidade com o meio urbano, para que viabilize a troca de seu trabalho com este meio. Isolado no meio rural, distante da cidade, o trabalhador do campo não tem a opção de deslocar uma parte da sua capacidade de trabalho para outras atividades além daquela que é a extensão da sua sobrevivência: a produção de subsistência.

\section{Considerações finais}

Como escreveu Derruau, "O modo de vida é a resposta de um grupo à organização econômica e social que the é imposta ou que ele impõe a si próprio". O movimento que assistimos é o da artificialização do meio, resultado de diferentes articulações do desenvolvimento do capitalismo contemporâneo no meio rural, oportunizando uma mudança no modo de vida. Quanto mais especializado, mais articulado com o meio urbano com o qual troca informações de toda ordem, se tornando cada vez mais semelhante ao do seu par urbano, bem como ficando dependente dos produtos da cidade, com a qual completa o conjunto de suas necessidades.

Em áreas de agricultura mais desenvolvida tecnologicamente, com grandes inversões de capital, onde a renda da terra é alta, a disciplina do trabalho é muito semelhante ao trabalho urbano, com jornadas de trabalho diário definidas, com deslocamento de pequenas vilas ou cidades para o local de trabalho. A divisão do trabalho segue a mesma lógica, com equipes de trabalho para a lavoura e outras para a pecuária bovina, procurando otimizar 0 maquinário para uma ou outra atividade, dentro de uma atividade empresarial e na busca da relação entre produtividade e rentabilidade constante.

A geografia do campo submete-se ao processo de urbanização do meio rural, na medida em que as vantagens locacionais artificiais superam as naturais. Mas isto ocorre onde a renda é alta ou existe a possibilidade de isto vir a acontecer. A análise dos sistemas de produção favorece a avaliação do patamar tecnológico e das alterações de hábitos e costumes de uma comunidade agrícola. Da indivisibilidade do trabalho ao aumento da divisão do trabalho capitalista empresarial, a produção familiar passa por um gradiente de especializações dos membros da família, inclusive resultando na transferência de alguns membros para a cidade, principalmente as mulheres, fenômeno recente denominado pela sociologia como "masculinização do campo".

Quanto maior a aproximação com os centros urbanos, e isto não requer apenas a aproximação física, mas a informacional, maior será a possibilidade de formas de produção na atividade agrícola familiar, aumentando sua especialização. Esta ocorrerá sempre que houver algum impedimento na produção mais capitalizada ou houver necessidade de mão de obra, onde a família preenche esta lacuna com as suas vantagens locacionais. Esta

Para0nde!?, Porto Alegre, v.13, n.1, p.21-45, 2020. http://seer.ufrgs.br/paraonde 
associação ou integração com a indústria (agro) conduz a unidade familiar camponesa à especialização, tornando-a uma parte importante no processo produtivo, como responsável pelo padrão de um determinado produto, estimulada por linhas de financiamento estatais, como o exemplo do Pronaf. Isto também a pressiona a deixar sua tradicional autonomia para se tornar cada vez mais consumidora dos produtos que não produz ou mesmo não pode mais produzir para seu consumo. Isto contribui enormemente para alterações no modo de vida, ainda que possam permanecer aspectos culturais que, muitas vezes, são incorporados ao processo de produção, agregando valor ao produto final das unidades familiares e empresariais. Quanto mais estreita a integração, mais especializada e empresarial tem que funcionar a gestão do trabalho, ainda que mantendo as características familiares que as definem como tal.

Já as unidades familiares com pouca ou nenhuma forma de integração tendem a se localizar nas áreas de menor renda da terra, ou seja, áreas com dificuldade de acesso ou falta de infraestrutura, o que dificulta sua inserção nas relações mercantis. Estas áreas, caracterizadas pelo isolamento, são cada vez mais raras no cenário da produção agrícola, pois representam aquelas unidades familiares que não entraram na seleção do acesso a alguma tecnologia, e na condição de permanência localizam-se em áreas distantes das conexões do mundo urbano. Tornam-se isoladas, também, das relações ou possibilidades de troca de mercadorias, infraestrutura e financiamentos e assistência de todo tipo disponibilizada no meio urbano.

Esta composição de fatores aqui analisados, que expressam diferentes combinações entre o estudo da renda da terra e sua influência sobre o modo de vida, reflete que a vida está em permanente movimento, como escreveu Brunhes: "Todos são animados por determinado movimento; é necessário estudá-los como se estudam os corpos em movimento: precisar o ponto do espaço e o momento do tempo em que se produzem; depois, indicar o sentido e observar a rapidez do próprio movimento".

\section{Referências}

BRUNHES, J. Geografia Humana. Rio de Janeiro: Fundo de Cultura, 1962.

CHAYANOV, A. V. Teoria dos sistemas não capitalistas. IN CARVALHO, H.M. (org.) Chayanov e o campesinato. São Paulo: Expressão Popular, 2014.

DERRUAU, Max. Geografia Humana. Lisboa: Editora Presente. 1982. 2 vol.

DUTRA, E.J. da S. A produção de fumo em perspectiva: a tipologia dos produtores de fumo no município de Canguçu, Rio Grande do Sul, Brasil. Tese de Doutorado em Geografia. Universidade Federal do Rio Grande do Sul. 2015. Disponível em:

https://www.lume.ufrgs.br/handle/10183/2/browse?value=Dutra\%2C+\%C3\%89d er+Jardel+da+Silva\&type=author

Acesso em 30 set. 2019.

Para0nde!?, Porto Alegre, v.13, n.1, p.21-45, 2020. http://seer.ufrgs.br/paraonde 
FALCADE, I. A paisagem como representação espacial: a paisagem vitícola como símbolo das indicações de procedência de vinhos das regiões Vale dos Vinhedos, Pinto Bandeira e Monte Belo (Brasil). Tese de Doutorado em Geografia. Universidade Federal do Rio Grande do Sul. 2011. Disponível em:

https://www.lume.ufrgs.br/handle/10183/36052

Acesso em 30 set. 2019.

KAUTSKI, K. A questão agrária. São Paulo: Proposta Editorial, 1980.

LENIN, V.I. Capitalismo e agricultura nos Estados Unidos da América: novos dados sobre as leis de desenvolvimento do capitalismo na agricultura. São Paulo: Ed. Brasil Debates, 1980.

MARTINS, J.S. Capitalismo e tradicionalismo: estudos sobre as contradições da sociedade agrária no Brasil. São Paulo: Pioneira, 1975.

MARTINS, J.S. Os camponeses e a política no Brasil: as lutas sociais no campo e seu lugar no processo político. $3^{\underline{a}}$ ed. Petrópolis: Vozes, 1986.

MARX, K. O Capital. Crítica da Economia Política. 2a ed. São Paulo: Nova Cultural, 1986. vol V.

MAZOYER, M. \& ROUDART, L.. História das agriculturas no mundo: do neolítico à crise contemporânea. São Paulo: editora da UNESP; Brasília: NEAD, 2010.

SANTOS, J. R. dos. A previdência rural em São José do Norte e impactos territoriais. CaderNAU. Cadernos do Núcleo de Análises Urbanas, vol. 3, n. 1, 2009. Disponível em:

https://www.seer.furg.br/cnau/article/view/4716

Acesso em 30 set. 2019.

WAIBEL, Leo. Capítulos de geografia tropical e do Brasil. Rio de Janeiro: IBGE, 1958.

WANDERLEY, M.B.N. Em busca da modernidade social: uma homenagem a Alexander V. Chayanov. IN CARVALHO, H.M. (org.) Chayanov e o campesinato. São Paulo: Expressão Popular, 2014. 